\title{
Escolas, cidades e seus patrimônios: dinâmicas escolares de patrimonialização cultural
}

\author{
Rodrigo Manoel Dias da Silva ${ }^{1}$
}

\section{Resumo}

Diversos estudos interdisciplinares que abordam as relações entre patrimônio e memória social têm demonstrado uma descentralização dos processos de patrimonialização cultural, cujo eixo estruturador desloca-se do Estado, enquanto ator privilegiado na seleção e conservação do que se convenciona como patrimônio, às comunidades e atores sociais, enquanto demandantes de políticas para o patrimônio e para a educação patrimonial. Nesse sentido, o contexto da redemocratização política no Brasil fez-se conjuntura favorável à redefinição do papel do Instituto do Patrimônio Histórico e Artístico Nacional, o Iphan (anterior Sphan), evidenciando alterações nas correlações de força entre atores governamentais e agentes sociais, a partir das quais coletividades historicamente ausentes ou silenciadas encontraram novas condições políticas e revitalizaram experiências de luta por cidadania e justiça social. Considerando as transformações operadas em tais concepções de patrimônio e suas influências sobre as políticas e as práticas de educação patrimonial no país, o artigo visa, por um lado, problematizar as diversas dimensões que interferem hoje nos processos de patrimonialização cultural e, por outro, refletir sobre a condição da escola enquanto agente ativo nos processos de salvaguarda das memórias e das culturas locais e regionais. Conclui com a afirmativa de que a educação escolar, na atualidade, faz-se tensionada pelas novas configurações do campo do patrimônio e pelos dilemas de uma sociedade democrática, em detrimento das décadas anteriores, nas quais fora produzida pelos princípios da homogeneização e da unidade nacional.

\section{Palavras-chave}

Patrimônio cultural - Escola - Educação patrimonial.

1- Universidade do Vale do Rio dos Sinos (Unisinos), São Leopoldo, RS, Brasil Contato: rodrigods@unisinos.br 


\section{Schools, cities and their heritage: school dynamics of cultural patrimonialisation}

\section{Abstract}

Many interdisciplinary studies approaching the relationship between heritage and social memory have shown a decentralisation of processes of cultural patrimonialisation, whose pivot moves away from the State, as a privileged actor in selecting and preserving what is agreed upon as heritage, and towards communities and social actors as demandants of policies for heritage and patrimonial education. In this sense, the context of political re-democratisation in Brazil was amenable to redefining the role of the Institute of the National Historical and Artistic Heritage, the Iphan (earlier Sphan), evincing changes in correlations of force between government actors and social agents, from which historically absent or silenced collectivities have found new political conditions and renewed experiences to fight for citizenship and social justice. Considering the transformations working in such conceptions of heritage and its influence on policies and practices of patrimonial education in the country, on one hand, this paper aims to problematise the several dimensions that at present interfere with the processes of cultural patrimonialisation and, on the other hand, to reflect upon the condition of the school as an active agent in the processes of preserving memories and local and regional cultures. It concludes with the statement that schooling today is coerced by the new configurations of the heritage field and by dilemmas of a democratic society at cost of earlier years, when it was produced by principles of homogenisation and national unity.

\section{Keywords}

Cultural heritage - School - Patrimonial education.

Pero es preciso levantar la vista de los árboles para ver el bosque, pues, más allá de estos problemas y conflictos recurrentes, el panorama está cambiando de manera radical (ENGUITA, 2016, p. 10).

\section{Apresentação}

Atualmente, diversos estudos têm demonstrado uma descentralização dos processos de patrimonialização cultural, cujo eixo estruturador desloca-se do Estado, enquanto ator privilegiado na seleção e na conservação do que se convenciona como patrimônio, às comunidades e atores sociais, enquanto demandantes de políticas para o patrimônio e para a educação patrimonial (ABREU, 2015; SILVA, 2015; IBARRA, 2016). Como observa a historiadora chilena Macarena Ibarra (2016), nesse cenário a comunidade passa a ser 
partícipe da patrimonialização em diversas etapas, como a identificação, o reconhecimento, o registro, a gestão e mesmo o uso desses patrimônios.

A partir de uma revisão sobre as transformações operadas nas concepções de patrimônio que têm orientado as políticas e as práticas de educação patrimonial vigentes no Brasil, o artigo visa, por um lado, problematizar as diversas dimensões que interferem nos processos de patrimonialização cultural e, por outro, refletir sobre a condição da escola enquanto agente ativo nos processos de salvaguarda das memórias e das culturas locais e regionais.

Para enfrentarmos tal problematização, organizamos o presente artigo em três seções textuais. Na primeira, realizaremos uma revisão acerca das concepções de patrimônio cultural predominantes na literatura brasileira, bem como sobre as transformações econômicas, socioculturais e educacionais transcorridas nessas políticas e os modos pelos quais favoreceram a emergência de novos processos de patrimonialização. Na segunda seção, almejamos perscrutar os fatores que têm influenciado essa paisagem sociocultural, a partir da qual o tema do patrimônio adquire novo dinamismo, e revisitar na teoria social contemporânea elementos heurísticos para a compreensão desse fenômeno. Por fim, almejamos evidenciar e analisar as dinâmicas escolares de patrimonialização cultural, a partir da narrativa de duas situações empíricas oriundas de experiências de campo relatadas pelo pesquisador em São Luiz do Paraitinga, SP, e Laguna, SC.

\section{A ideia de patrimônio no Brasil e suas transformações}

A conferência do Escritório Internacional de Museus, realizada em Atenas no ano de 1931, inaugura uma sequência de convenções, acordos e cartas públicas de legitimidade internacional que tratariam de legislar sobre o patrimônio cultural ao longo do século XX. A Carta de Atenas, documento resultante do encontro, configurou-se em uma carta de princípios acerca da adoção de procedimentos comuns para a preservação de monumentos artísticos e históricos, entre os países europeus signatários do referido texto. Segundo Márcia Chuva (2009), até o século XIX, predominavam duas correntes de pensamento quanto à concepção de restauração do patrimônio (arquitetônico) de uma nação, a saber:

Tratava-se de optar entre manter em evidência as características físicas adquiridas historicamente pelo monumento, esclarecendo as suas diversas formas de permanência ao longo do tempo, ou de reconstituir as suas formas originais relativas ao momento e aos objetivos para os quais fora construído o documento (sua razão arquitetônica) (CHUVA, 2009, p. 318).

Importa observarmos que essa opção dizia respeito à necessária ampliação das noções de valores nacionais simultaneamente em que deveriam ser considerados outros de natureza mais global ou geral, como valores universais de civilização. Como a própria autora observa, "engendrava-se, então, a construção de uma 'ordem mundial' baseada em valores específicos, europeus” (CHUVA, 2009, p. 319). Ainda que esse dilema não tenha se diluído por completo, a Carta de Atenas tornou-se um documento que influenciou ações de Estado no campo patrimonial em todo o Ocidente. No Brasil, essa discussão emerge na segunda metade da década de 1930, capitaneada por vários intelectuais da geração modernista de 1922, mediante a criação do Serviço para o Patrimônio Histórico e Artístico Nacional, o Sphan. 
Os princípios dessa discussão em nosso país foram muito marcados pelas contradições entre a europeização (enquanto desejo de tornar-se uma civilização avançada) e a brasilidade, “[...] que visava, dentre outros aspectos, a busca dos meios propriamente brasileiros de 'produção da nação', característica que marcou os princípios da arquitetura modernista no Brasil e também o movimento modernista [...]” (CHUVA, 2009, p. 320). Em alguma medida, essa contradição se torna evidente pela reapropriação do Barroco enquanto expressão monumental do país, uma vez que essa tendência artística era, até então, vista como desqualificada.

Os bens tombados pelo Sphan buscavam autenticar e reelaborar a influência de Portugal na formação do Brasil. "Desta forma, era frequentemente rejeitada qualquer influência indígena ou africana, até mesmo na produção artística das Missões jesuíticas do Sul" (CHUVA, 2009, p. 324), consolidando representações eruditas, barrocas e lusitanas do patrimônio brasileiro. Os intelectuais do Sphan reinterpretavam aspectos da sociedade brasileira e autenticavam uma história particular que vinculava cultura e nação. Assim,

A associação entre tradição e modernização que configurou particularmente o drama da modernidade no Brasil teve, portanto, nesse âmbito de atuação do Sphan, uma de suas mais profícuas expressões e realizações, pois ela confırmava a crença de que, enfım, se concretizava o sonho modernista de demarcação de uma nova temporalidade para a nação brasileira - a "brasilidade" - sem que houvesse perda das suas particularidades (CHUVA, 2009, p. 333).

Ainda que de maneira muitas vezes discutível, os técnicos do Sphan, em sua maioria arquitetos, foram arquitetando a memória nacional (CHUVA, 2009) e produzindo um léxico próprio para as políticas para o patrimônio no país. A partir da década de 1970, iniciase uma ampliação conceitual da ideia de patrimônio, mas, por diversos motivos, ainda predominou no Brasil até o final da década de 1990 o tombamento enquanto expediente privilegiado de patrimonialização (LONDRES, 2009). A própria Constituição de 1988 ainda atribuiu centralidade a essa prática de preservação.

Entre a afirmação e o reconhecimento das manifestações culturais e os limites acarretados a partir do uso dos imóveis, as práticas e processos de tombamento evidenciaram muitos conflitos. Outra característica das políticas patrimoniais brasileiras voltadas ao tombamento foi a centralidade do Estado enquanto demandante de tais práticas. Cecília Londres (2009, p. 183) observa que, até a década de 1970, “[...] a grande maioria das solicitações tinha origem na própria instituição federal [...]”, situação que, nas décadas subsequentes, passou a se alterar.

A partir da década de 1990, começam a surgir processos de solicitação de tombamento oriundos da sociedade civil.

É possível, portanto, qualificar a participação da sociedade nos tombamentos, a partir da análise de processos: se, por um lado, os pedidos de tombamento deixaram de ser iniciativa quase que exclusiva da instituição, os mecanismos de decisão continuaram restritos aos órgãos técnicos da administração central e, salvo casos excepcionais, não foi possível detectar muitos casos de mobilização de setores da sociedade no sentido de pressionar o Sphan na prática de preservação (LONDRES, 2009, p. 185). 
Entre as décadas de 1970 e 1980, inicia-se uma redefinição dos valores que orientavam e justificavam um tombamento. Valor histórico, valor artístico, valor excepcional, valor nacional e os conceitos de centro histórico e de entorno entram discussão. "A própria competência exclusiva do Sphan de atribuir valor a bens enquanto patrimônio histórico e artístico nacional se tornou também objeto de discussão e de reflexão" (LONDRES, 2009, p. 188). Esse tensionamento foi positivo uma vez que, associado a outras condições mais amplas, favoreceu uma maior abertura às concepções de patrimônio, em geral, e de patrimônio brasileiro, em particular.

Na década de 1980, começaram a chegar ao Conselho pedidos de tombamento dentro da ideia de "novos programas": bens representativos da etnia afro-brasileira (Terreiro da Casa Branca, BA e Serra da Barriga, AL); das diferentes correntes de imigração (Casa Presser, RS; Casa do Professor e Escola Rural, e Cemitério protestante, SC, testemunhos da imigração alemã; Casarão do Chá, SP, testemunho da imigração japonesa; cidade de Antônio Prado, RS, testemunho da imigração italiana; marcos da história da ciência e da tecnologia no Brasil (Casa de Saúde Carlos Chagas e Estação Ferroviária de Lassance, MG; Escola de Enfermagem Ana Neri, Fundação Osvaldo Cruz e Hospital São Francisco de Assis, RJ; inúmeros exemplares da arquitetura em ferro, como pontes, mercados, caixas d'água, açudes etc.; novos exemplares da arquitetura civil, como curtume, fábricas e conjuntos habitacionais populares; e até fazeres, objeto da proposta de tombamento da Fábrica de Vinho de Caju Tito Silva, Paraíba) (LONDRES, 2009, p. 206).

Em síntese, podemos observar que nossas primeiras definições de patrimônio se orientaram pelo desejo de civilização, mobilizado pelo Barroco e pelo patrimônio material remanescente da presença portuguesa no Brasil. Essa definição centrava-se no Estado enquanto personalidade jurídica definidora das políticas patrimoniais e, ideologicamente, direcionada à consolidação da unidade nacional. No entanto, as situações presentes na citação acima evidenciam que, nos últimos anos, houve uma expressiva ampliação do que se entende por patrimônio e, com efeito, de suas expressões no campo sociocultural. Como observado por Silva (2016), a educação patrimonial, mesmo que a nomenclatura tenha sido empregada apenas no final da década de 1980, assumiu essa operação de enquadramento das memórias nacionais (POLLAK, 1989) como elemento mais substantivo de suas intervenções. Educar para o patrimônio converteu-se, por algumas décadas, em estratégia fundamental para a unidade da nação e para sua própria produção.

0 contexto da redemocratização política fez-se favorável à redefinição do papel do Instituto do Patrimônio Histórico e Artístico Nacional, o Iphan (anterior Sphan), na sociedade brasileira. No período presidencial de Fernando Henrique Cardoso (1995-2002), foi criado um programa de patrimonialização do imaterial em decorrência da Recomendação para a Salvaguarda da Cultura Tradicional e Popular, de 1989 (ABREU, 2015). Em 2000, pelo Decreto n. 3551, foi criado o Programa Nacional de Patrimônio Imaterial, o qual

Tratava de estimular a própria sociedade a construir uma mentalidade de promoção e proteção ao patrimônio imaterial, propondo ações e estabelecendo parcerias. Este aspecto me parece central, pois reflete o espírito dos novos tempos, em que o Estado aparece como fomentador e regulador de uma 
política que deve necessariamente envolver vários setores da sociedade: as comunidades, os especialistas, as organizações não-governamentais, as empresas privadas, as universidades (ABREU, 2015, p. 79).

0 decreto acima mencionado estabeleceu dois novos mecanismos de chancela patrimonial, quais sejam: o inventário de bens culturais imateriais e o registro. Se as políticas até então protegiam bens tangíveis através do tombamento, esse texto legal possibilitou que bens culturais intangíveis também pudessem ser salvaguardados. Metodologicamente, tal deliberação exigiu que o Iphan desenvolvesse metodologias mais apropriadas para tal finalidade, dentre estas o Inventário Nacional de Referências Culturais (INRC), o qual posteriormente inspirou uma abordagem metodológica para a educação patrimonial no âmbito do Programa Mais Educação.

Além da complexificação do campo das políticas patrimoniais, vista pela chegada de novos atores em cena (patrocinadores, agentes de ONGs, comunidades, produtores culturais, atores políticos locais etc.), uma das principais transformações nesse campo foi a possibilidade de inversão na lógica dos demandantes de tais processos. As comunidades passam a ver a patrimonialização (registro, inventário ou tombamento) como um recurso (YÚDICE, 2004) para diversos fins. Exemplar, nesse sentido, foi o registro patrimonial da arte Kusiwa, pintura corporal e arte gráfica dos Wajãpi, no Estado do Amapá, cuja manifestação foi assentada no Livro dos Saberes.

A particularidade dessa situação refere-se à iniciativa da candidatura ter sido originada das principais lideranças e de professores indígenas Wajãpi.

\begin{abstract}
A arte Kusiwa é definida, em poucas palavras, como um sistema de representação, uma linguagem gráfica dos índios Wajãpi do Amapá que sintetiza seu modo particular de conhecer, conceber e agir sobre o universo. Ainda segundo este documento, o sistema gráfico Kusiwa opera como um catalisador para a expressão de conhecimentos e práticas que envolvem relações sociais, crenças religiosas e tecnologias, até valores estéticos e morais (ABREU, 2015, p. 82).
\end{abstract}

Em tais contextos, emergem novos sujeitos do direito coletivo, defendendo seus interesses e inscrevendo na pauta pública suas demandas e seus direitos. Tornam-se evidentes alterações nas correlações de força entre atores governamentais e agentes sociais, a partir das quais coletividades historicamente ausentes ou silenciadas encontram novas condições políticas e revitalizam experiências de luta por cidadania e justiça no Brasil. Além disso, as políticas patrimoniais, aos poucos, deixam de ser atributo de falas autorizadas pelo Estado e se convertem em "falas plurais tecidas em redes em que interagem diversos agentes" (ABREU, 2015, p. 72). Em síntese, inicia-se uma tendência à "patrimonialização das diferenças" (ABREU, 2015), na qual concede-se cada vez mais atenção às noções de singularidade e de especificidade cultural.

\title{
Do Barroco à patrimonialização das diferenças: do patrimônio oficial à escola
}

Quando examinamos, na seção anterior, as transformações no sentido, nas políticas e nas práticas de patrimonialização cultural no Brasil identificamos um conjunto de 
deslocamentos de significação e de processos históricos que podem ser condensados na transição que intitula a presente seção. Contudo, tal transição não ocorreu de modo direto, unilateral ou destituído de conflitualidades.

Nessa elaboração, matizada por leituras em ciências humanas e sociais, diversos fatores influenciam a formação desse cenário sociocultural e exigem um esforço de problematização. 0 tema do patrimônio tem adquirido, nas últimas décadas, um dinamismo próprio, a ser observado nas modificações substanciais de seus conceitos e na inflação de ações denominadas como patrimoniais (ROTMAN, 2010). Importante mencionar que, além da influência de mecanismos internacionais sobre o campo, como o caso da Unesco, os novos desenvolvimentos conceituais do termo patrimônio na teoria antropológica, em particular, e nas teorias sociais, em geral, instigam modificações no tratamento do próprio termo.

Segundo Mónica Rotman (2010), três seriam as discussões da antropologia que teriam contribuído diretamente na ressignificação no debate público sobre patrimônio.

Em primeiro lugar, a adoção de um enfoque do patrimônio que apostava em um tratamento diferente dos bens culturais, não mais centrado no sentido interno dos objetos, mas nos processos de produção e circulação social e nos significados que lhes são atribuídos por diferentes receptores. Assim, o patrimônio não seria mais conceituado como "acervo cultural", mas como construção social [...] (ROTMAN, 2010, p. 24, tradução nossa).

A segunda discussão refere-se à ampliação do patrimônio valorizado, considerando cultura em perspectiva mais alargada, eivada por expressões mais variadas e diversificadas, permitindo seu reconhecimento por outros grupos. Em outros termos, Rotman enfatiza que, tal como elementos patrimoniais da dita alta cultura, as culturas produzidas pelas classes populares também seriam detentoras de manifestações patrimoniais. A terceira discussão, por fim,

Uma valorização diferente dos critérios de temporalidade associados usualmente aos bens e práticas imersos em processos de patrimonialização. Trata-se de processos de "atualização" do patrimônio, para que este abarque não apenas os bens produzidos no passado, mas também aquelas expressões da cultura que têm lugar na atualidade (ROTMAN, 2010, p. 25, tradução nossa).

Assim, seriam contributos do campo teórico da antropologia aos debates públicos sobre patrimonialização o entendimento de que: (a) os patrimônios são socialmente construídos; (b) as manifestações expressivas das culturas populares são reconhecidas como patrimônio; e (c) a atualização da percepção patrimonial das expressões culturais (de temporalidade presente).

Outra dimensão a ser analiticamente considerada diz respeito ao papel ocupado pelo patrimônio na construção da nação e, com efeito, dos Estados nacionais. De acordo com Canclini, o Estado mantém uma relação ambivalente com o patrimônio. Os patrimônios são valorizados como elementos integradores da nacionalidade, isso fez com que inúmeros países tenham realizado muitos investimentos em políticas culturais, sobretudo na construção de museus e na preservação da memória. No México, por exemplo, fez- 
se "com que os artesanatos de diversos grupos étnicos, os símbolos históricos e alguns saberes regionais transcendessem sua conexão exclusiva com a cultura local” (CANCLINI, 1994, p. 102).

\begin{abstract}
Não obstante, como todo Estado moderno, ao promover o patrimônio o Estado mexicano tendeu a converter essas realidades locais em abstrações político-culturais, em símbolos de uma identidade nacional em que se diluem as particularidades e os conflitos. Às vezes, o Estado se interessa pelo patrimônio a fim de frear o saque especulativo; noutros casos, porque o alto prestígio dos monumentos é um recurso para se legitimar e obter consenso; noutros ainda, assinala Carlos Monsiváis, por simples complacência cenográfica (CANCLINI, 1994, p. 102).
\end{abstract}

0 fortalecimento dos Estados nacionais exigiu reincidentes estratégias de legitimação simbólica e política, em nome, inúmeras vezes, da unidade nacional ou da produção de uma identidade nacional, como Londres (2009) e Chuva (2009) destacaram acima sobre a realidade brasileira. Memória, patrimônio, educação e imprensa ocuparam posições importantes na construção do imaginário nacional. A transição ao século XXI trouxe consigo a fragilização dos Estados nacionais, principalmente em suas perspectivas de homogeneização e de padronização cultural.

Deslocamentos populacionais massivos, acelerada urbanização, globalização econômica, mundialização da cultura, multiculturalismo, intervenções da Unesco e de outras organizações internacionais, movimentos sociais e demandas por reconhecimento cultural. Diversos são os fatores que parecem definir tal fragilização dos Estados nacionais, contudo todos parecem convergir para suas implicações sobre o campo do patrimônio cultural, das memórias e das identificações coletivas em diferentes condições nacionais. 0 protagonismo do Estado na definição e promoção patrimonial parece estar sob suspeita.

Joël Candau (2016), por sua vez, analisa semelhantes processos ao constatar o esgotamento e o colapso das grandes memórias organizadoras. Conforme a argumentação do antropólogo francês,

Essas grandes categorias organizadoras de representações identitárias coletivas são mais eficazes quando dispõem, dispersos em todo o corpo social, de meios de memória: escola, igreja, Estado, família, que com suas práticas e ritos diversos difundem e fazem viver essas grandes memórias organizadoras (CANDAU, 2016, p. 182).

Tal foi o lugar ocupado pela escola laica no Ocidente, a qual, através da publicação e circulação de manuais e de toda a forma escolar (DUBET, 2011), consolidou e popularizou a memória republicana, a formação do cidadão e a moral do dever. Nos termos de Candau, o Republicanismo foi uma memória organizadora uma vez que garantiu a transmissão de um tempo na forma de uma memória longa. Memória organizadora é uma memória forte que transmite todo um corpus memorial, capaz de organizar e orientar identidades coletivas (CANDAU, 2016).

Hoje, há um recuo nas grandes referências memoriais, o que corresponde "[...] ao desaparecimento de um 'princípio explicativo único' e ao retrocesso de 'memórias unitárias'[...]" (CANDAU, 2016, p. 183). Abre-se um processo geral de individualização das memórias: 
Todo um arsenal de argumentos, figuras retóricas e noções diversas são utilizadas para dar conta dessa evolução, considerada mais como uma verdadeira mutação e, inclusive, como uma "fratura". A modernidade (incluindo a pós-modernidade ou a sobremodernidade) seria, a partir de então, indiferente aos profetas, marcada pela negação do sagrado, pelo desencantamento do mundo, pelo desprezo ao religioso, pelo ocaso dos deuses e a retomada das observâncias. Outros evocarão a perda da densidade ou o fim das memórias monopolizadoras em benefício das memórias híbridas, a desestabilização de todas as memórias autorizadas, o deslocamento pura e simplesmente de toda outra memória que não seja imediata e funcional, a derrota da memória, a crise de identificações locais e identificações de linhagem, o retrocesso das visões totalizadoras, o descrédito das referências centrais, a diluição do sentimento coletivo, o caráter de inautenticidade dos contatos interpessoais e de nossa relação com o passado (CANDAU, 2016, p. 185).

Através dessa compilação de termos que intelectuais têm utilizado para nomear esse fenômeno, o estudioso francês nos oportuniza constatar que o retrocesso das memórias organizadoras, sobretudo aquelas que adensavam os Estados nacionais, é dificilmente contestável. A transformação recente sofrida pelo conceito de patrimônio permite diversas analogias com o raciocínio de Joël Candau. Uma destas analogias pode ser denominada como "dessacralização do patrimônio" (IBARRA, 2016). A dessacralização permite a participação das comunidades nos processos de patrimonialização, atualizando permanentemente o que se entende por patrimônio.

De um bem sagrado a algo manipulado pelas pessoas na vida cotidiana (IBARRA, 2016). Como observado acima por Regina Abreu, essa tendência inverte a lógica da seleção patrimonial, mas, sobretudo, empodera comunidades e atores definidos como minorias e enceta dinâmicas de legitimação social do patrimônio.

Ao produzir um diagnóstico sobre a realidade chilena, Macarena Ibarra identifica o peso que a participação comunitária ocupa na seleção, na legitimação e no uso do patrimônio cultural naquele país. As demandas de atores e comunidades e a outorga de Zonas Típicas (ZT, processo de definição de patrimônio vigente no referido contexto nacional) excedem às solicitações do Estado. No período de 2001 a 2015, tramitaram 24 solicitações, a saber: sete por parte do Estado; quatro por parte de especialistas; duas por parte de governos locais; onze por comunidades vicinais.

Nesse contexto, diversos atores passam a engajar-se em ações patrimoniais. Uma prática que merece destaque nesse contexto é a educação patrimonial, primeiramente através de experiências informais, que assumem o espaço da cidade como espaço formativo ou pensam a cidade como "território de lugares de memórias e de histórias" (KURI, 2006, p. 105).

As iniciativas de educação patrimonial não formais têm tanto impacto na comunidade como aquelas destinadas a crianças e jovens em estabelecimentos escolares. A partir de um cadastro realizado no Chile sobre as diversas iniciativas a nível local em educação patrimonial, se pode observar também que o foco dessas ações se amplia a distintos grupos etários. [...] Tais iniciativas correspondem a projetos, planos e programas orientados ao resgate, transmissão e difusão de conhecimento através de cursos, guias e material escrito ou audiovisual destinado à capacitação, formação e criação de conhecimento em torno do patrimônio de uma cidade ou localidade de algum tipo, excluindo aquelas iniciativas formais que tenham que ver com escolas e outras 
instituições educativas, não obstante projetos que se possa escolarizar ou formalizar (IBARRA, 2016, p. 31, tradução nossa).

Por outro lado, sobretudo em municípios onde não há processo oficial de patrimonialização cultural chancelado por órgão patrimonial do Estado, a escola atua a fim de evitar a "morte social do patrimônio cultural" (GARCÍA, 2016). Muitas escolas, inclusive brasileiras, mobilizam práticas pedagógicas a fim de salvaguardar elementos que são considerados patrimônios materiais e imateriais de sua localidade. Ora de modo informal, ora de modo formal, com objetivos multifacetados e diversos interesses em jogo, como em qualquer dinâmica sociopolítica, as instituições de ensino desenvolvem dinâmicas de patrimonialização. Na contemporaneidade, quando acompanhamos a consideração das diferenças e diversidades nessas proposições (ABREU, 2015), faz-se necessário examinarmos essa face da proteção dos patrimônios brasileiros.

\section{As escolas e os patrimônios da cidade}

A partir de aproximações etnográficas, temos acompanhado diversas experiências escolares situadas em municípios brasileiros que sofreram processo de patrimonialização cultural, nos quais ocorre o desenvolvimento sistemático de ações em educação patrimonial, intencionando verificar os modos pelos quais os atores escolares apropriam-se dos bens patrimoniais oficializados pelo Estado. Contudo, em uma experiência promovida em Laguna, no estado de Santa Catarina, e outra em São Luiz do Paraitinga, no estado de São Paulo, ainda que díspares, encontramos elementos que as diferenciavam do conjunto dos demais casos presentes no estudo. Assim, mesmo considerando a baixa institucionalidade da educação patrimonial no contexto das políticas para a escolarização ou para a cultura no país, nos dois contextos verificamos tendências que desviavam à referida tendência e evidenciavam um certo protagonismo dos atores escolares na salvaguarda de suas memórias e de seus patrimônios.

Para a análise que segue, utilizamos como fontes, para além das observações etnográficas desenvolvidas com regularidade nos municípios e nas escolas, a realização de entrevistas com atores selecionados, a consulta de informações disponíveis na rede mundial de computadores e o recurso fotográfico a partir das visitas realizadas.

Nessas aproximações, assumimos como perspectiva de abordagem a relação entre a cidade e a educação escolar tal como interpretadas na pedagogia social formulada por Jaume Trilla (1993). Segundo o estudioso, é possível identificarmos três dimensões relacionais que vinculam as experiências escolares aos contextos urbanos. Primeiramente, pensarmos a cidade como contexto da educação, assumindo a urbanidade enquanto condição ou lócus para o fenômeno educativo em suas múltiplas possibilidades. Em seguida, considerarmos a cidade como meio (ou veículo) da educação, interpretando a primeira não apenas como entorno, mas como ator dos processos educacionais e das formas socializadoras. Por último, Trilla observa que a cidade pode ser o conteúdo educativo, ou seja, refletirmos sobre as possibilidades de aprender a cidade, como importante elemento curricular.

Para uma observação teórico-metodológica, cumpre registrarmos ainda que, acompanhando a elaboração de Ádrian Gorelik (2005) não devemos investigar as cidades 
em busca de ontologias ou de sentidos relativamente determinados, mas investigarmos as formas espaciais urbanas como construção. Para tal, não deveríamos produzir abordagens sobre a cidade desconhecendo seus significados históricos e sua condição temporal. Do ponto de vista metodológico, o argentino nos provoca a reinventarmos nossa maneira de observar a cidade. Tal como um flâneur, percorrermos a cidade a partir de seus fragmentos dispersos, buscando o sentido autônomo de nossos passos, construindo significados liberados de toda marca da própria cidade, mas considerando-a como derivação de múltiplos processos, os quais precisamos cartografar e analisar.

\section{a) Educação patrimonial na cidade de São Luiz do Paraitinga, SP}

0 Ginásio Estadual de São Luiz do Paraitinga tem sua origem na Lei n. 5974/1960 e foi instalado no município homônimo no ano de 1962. Alterada pela Lei n. 10.678/1968 e pelo Decreto n. 52.582/1970, a denominação Colégio Estadual Monsenhor Ignácio Gióia é assumida em homenagem a um destacado pároco que atuou por muitos anos na cidade. Atualmente atendendo o ensino médio, verifica-se que muitos e muitas jovens matriculados na instituição são atuantes em diversos grupos culturais tradicionais no município, caso do Carnaval de Marchinhas, dos festejos juninos e da Festa do Divino Espírito Santo.

São Luiz do Paraitinga é um município paulista localizado na região da Serra do Mar, próximo a Taubaté e Ubatuba. Teve parte significativa de seu centro histórico tombado pelo Condephaat (órgão estadual de patrimônio), no ano de 1982, e, em 2009, teve decretado seu tombamento provisório pelo Iphan. No entanto, no começo de 2010, parte significativa de seus casarões remanescentes do Período Imperial foi destruída por uma grande enchente do Rio Paraitinga, que margeia o centro da cidade, após uma forte sequência de chuvas. Em meio aos processos de reconstrução da cidade e da vida das pessoas, a diversidade expressiva da cultura popular presente na vida do lugar ganhou evidência. Atores culturais de diferentes segmentos desenvolveram projetos e iniciativas em todo o estado de São Paulo a fim de angariar recursos para a reconstrução da cidade.

Uma das estruturas danificadas foi a do Colégio Estadual Monsenhor Inácio Gióia, a qual precisou ser integralmente reconstruída. Ocorre que, por não se tratar de prédio tombado, o prédio escolar foi refeito aos moldes de uma escola padrão, em obra constituída por vigas de concreto. No entanto, nesse processo ativo de reconstrução do lugar, os atores escolares começaram a patrimonializar as dimensões intangíveis de seu patrimônio e de sua cultura, fortemente marcadas pelo imaginário caipira (de formação rural), do Carnaval de Marchinhas, do folclore, do catolicismo popular, dentre outras.

Nesse projeto, a escola contou com a participação do artista plástico local (naïf), José Carlos Monteiro, servidor da instituição em vias de aposentadoria e reconhecido regionalmente por suas obras, o qual se dispôs a transpor imagens da cidade e de sua cultura, algumas já retratadas em seu trabalho, para o concreto do novo prédio. A escola ganhou vida e o prédio escolar nova rotina, uma vez que os estudantes, dia a dia, acompanhavam o patrimônio local sendo retratado em sua escola. 0 mais interessante das discussões que acompanhamos na escola se refere ao fato de ela identificar seu protagonismo na patrimonialização. De modo simultâneo, imediatamente após a enchente, o Iphan 
consolidou o tombamento defınitivo da cidade, no que tange às dimensões materiais do patrimônio, e a escola ativou iniciativas de salvaguarda do patrimônio intangível, por iniciativa própria.

Caminhando pelos corredores da escola, acompanhamos o trabalho de José Carlos e verificamos o interesse dos estudantes pelas imagens da cidade. A enchente vivenciada no município ainda estava presente nas conversações cotidianas e, mediante entrevistas, identificamos que as motivações de José correspondiam a essa situação crítica. Neste sentido, o artista e funcionário público menciona:

No momento, na escola em que trabalho, estou fazendo um trabalho para deixar para os alunos, tudo que se passou em São Luiz, tudo que eu vi e posso deixar. São painéis de pintura na parede. São murais. Ali eu estou contando as histórias, as lendas que São Luiz tem, mostrando o patrimônio arquitetônico (os sobrados de antigamente), as igrejas. Tudo que mudou ao longo do tempo (José Carlos, funcionário público).

Figura 1- Registros do patrimônio (l)

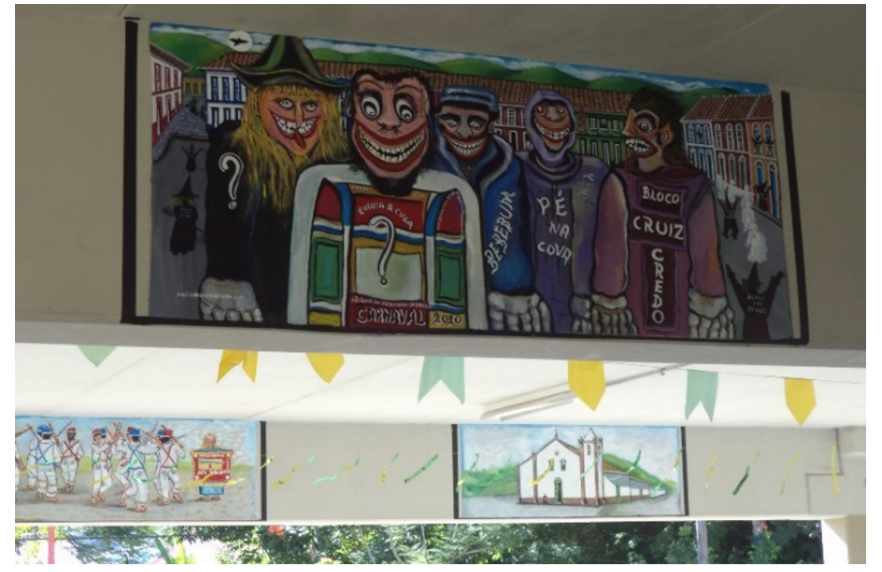

Figura 2- Registros do patrimônio (II)

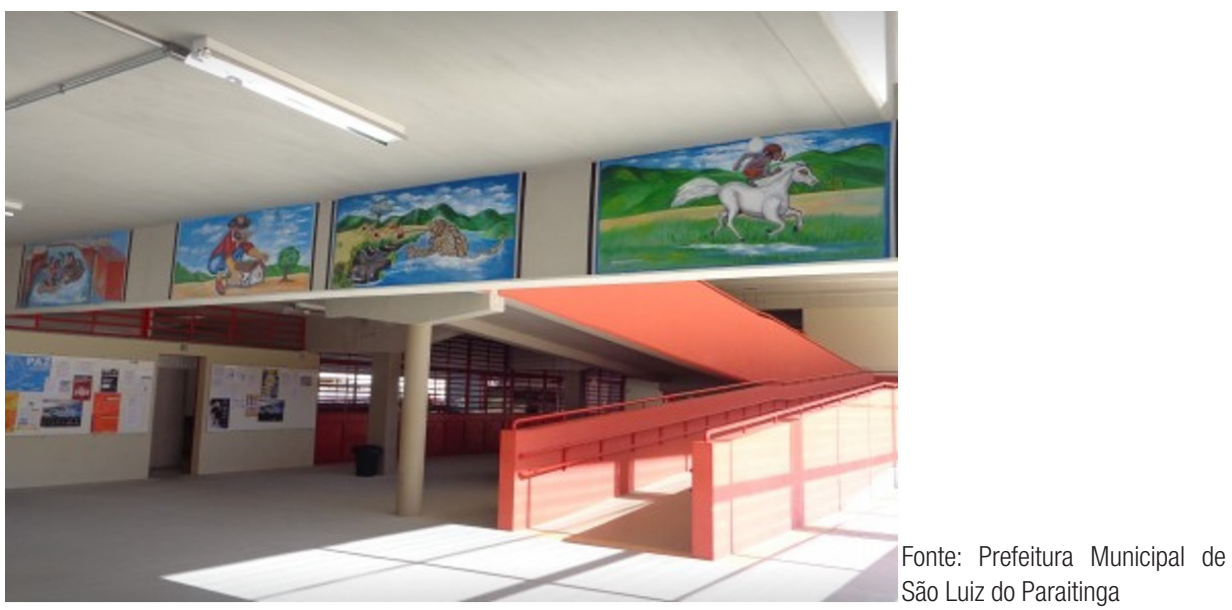


Como evidenciam as Figuras 1 e 2, o trabalho do artista luizense visa inventariar e representar diversos elementos materiais e, principalmente, imateriais de São Luiz do Paraitinga. Seu relato define essa ação de educação patrimonial como uma forma de legado, tanto de um funcionário público que completa 32 anos de serviço no mesmo educandário, mas também de um artista plástico engajado em causas culturais no lugar.

Como eu sou também artista plástico da cidade [...] faço a minha parte como artista. E a minha parte sempre foi defender o patrimônio cultural da cidade, o patrimônio artístico e cultural que seriam as construções de São Luiz. Desde pequeno, eu admiro essa cidade, sou daqui, nasci aqui (José Carlos, funcionário público).

\section{b) A Escola Manoel Gregório de Bem em Laguna, SC}

Laercio Vitorino dos Santos, 53 anos, é professor em Laguna, no estado de Santa Catarina. Com formação acadêmica em história e mestrado em educação, efetivou-se no cargo de professor da rede pública estadual ainda em 1990 e foi atuar em uma comunidade rural do município, no Distrito do Ribeirão Pequeno, na Escola Gregório Manoel de Bem.

De início, ao preparar suas atividades letivas, indagou os estudantes sobre questões de identidade cultural, tema que lhe era muito caro. Tendo em vista que a origem histórica de Laguna está vinculada à chegada dos açorianos ao Brasil e ao próprio fato de o município ser um patrimônio cultural reconhecido por órgãos oficiais, o professor considerava que a base cultural açoriana estaria presente nos discursos e nas práticas cotidianas de seus alunos. Suas interpelações obtinham desconhecimento e, segundo seus termos, vergonha como resposta. Como destaca em livro:

Nossas crianças pareciam envergonhar-se da própria cultura: na sala de aula diziam que não apreciavam a brincadeira do boi de mamão, mas nas festas juninas estavam embaixo do boi brincando; na hora do recreio deixavam o lanche da escola para comer cachorro-quente, salgadinho ou refrigerante no bar, mas em casa comiam batata doce, aipim no café e pirão de peixe no almoço (OLIVEIRA, 2010, p. 19).

Tais constatações desencadearam a produção de uma experiência de educação patrimonial de longa duração. Inicialmente, por volta do ano 2000, professor e alunos começaram a caminhar juntos pelo distrito rural do Ribeirão Pequeno e, com câmera em punho, coletaram imagens da história dos lugares e das pessoas. Encontraram referências sobre os brinquedos e as brincadeiras, os engenhos, as artes da pesca e dos pescadores, o boi de mamão, os ternos de reis, a culinária açoriana e as crendices (OLIVEIRA, 2010).

Em seguida, começaram a reconstruir lugares do bairro dentro da escola, em uma Feira Cultural. Entre 2001 e 2004, foram a campo entrevistar os idosos das comunidades, visando recuperar suas memórias daquilo que viveram no Ribeirão Pequeno e adjacências, bem como histórias e lembranças de como viviam seus antepassados. Em 2004, essa experiência foi premiada pelo concurso Tesouros do Brasil, obtendo o primeiro lugar na categoria Memória. A referida premiação intensificou as visitas aos moradores e a experiência escolar, mediante apoio do Iphan, converteu-se em projeto de livro sobre o Ribeirão Pequeno. 
A partir de 2007, o projeto tornou-se o Grupo Cultural Casa da Dindinha (Figura 3), envolvendo ações de conservação patrimonial e ações folclóricas. Referências às identidades dos imigrantes açorianos são progressivamente reconstruídas no cotidiano escolar através de uma exposição itinerante, indumentária típica, grupo de danças e músicas do arquipélago dos Açores, grupos de artesanato (confecção de bonecas de pano, louças de barro, pião, balaios etc.), grupo de cantadores (folias de reis, boi de mamão, pau de fita, chimango). Há, hoje, uma sala da escola destinada ao acervo de objetos coletados na comunidade que visa demonstrar como viviam os antepassados açorianos, o lugar recebe a denominação de Casa da Dindinha, em referência ao modo pelo qual os imigrantes chamavam suas avós.

Figura 3- Grupo escolar de cultura açoriana

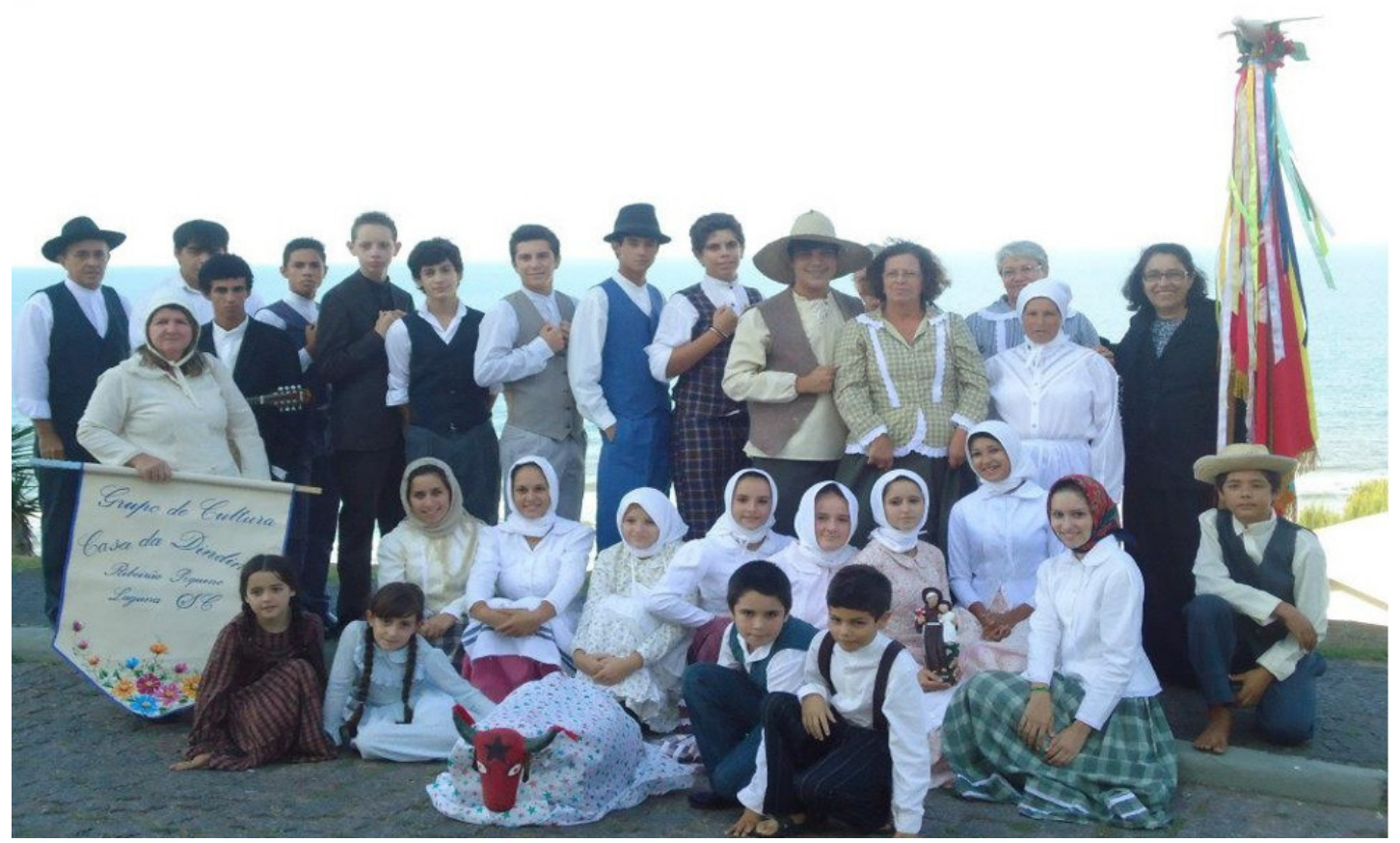

Fonte: Casa da Dindinha (http://casadadindinhalaguna.blogspot.com.br/)

Esses espaços são regularmente visitados por escolas e por universidades, como a Udesc, da UFSC, da Unoesc e da Unisul. Em diálogo, Laércio destaca suas motivações:

Eu sou apaixonado por cultura, eu sou apaixonado por cultura, eu acho que a identidade cultural de um povo é fundamental. Ela permeia as raízes. É, pelo menos, tu saber onde estão as tuas origens. Como professor de história fui me dedicando a isto assim..., a buscar, a resgatar não, por que tu não consegue resgatar a nenhuma cultura, não existe um resgate, mas pelo menos ver o 
que estava na memória destes velhos, ver como era o jeito de ser dos antigos e até para ver como hoje se manifesta, como esta gurizada está se manifestando isto que ficou lá atrás, então foi isto que foi me motivando (Laércio, professor).

Dessa maneira, diversas dimensões expressivas vão sendo incorporadas às práticas pedagógicas. Ao mesmo tempo, em entrevista, Laércio define sua experiência de educação patrimonial como

Um trabalho de reconstrução daquilo que estava perdido. Hoje, assim, eu consegui fazer com que esta juventude valorizasse seus velhos e com que os próprios velhos se valorizassem, entendeu? Aquilo que para eles era vergonhoso hoje é destaque, eu acho que, de certa maneira, todo este trabalho fez com que o pessoal percebesse o valor daquilo que eles não estavam mais valorizando, daquilo que eles estavam começando a ter vergonha (Laércio, professor).

\section{Considerações finais}

Como bem argumentou Patrícia Ramirez Kuri, os centros históricos são espaços públicos, lugares privilegiados para a convivência, o encontro e a atividade, uma vez que "traçam pontes entre os sentidos de continuidade individual e coletiva" (2006, p. 107, tradução nossa). Nesse contexto de dessacralização dos patrimônios (IBARRA, 2016) e de patrimonialização das diferenças (ABREU, 2015), as dinâmicas que delineiam os processos patrimoniais evidenciam o declínio do potencial monoidentitário dos Estados Nacionais (SILVA, 2015) e novos atores e comunidades assumem o protagonismo nas políticas patrimoniais. No Brasil, como a análise acima procurou evidenciar, diversas escolas têm se comprometido com essa tarefa.

0 debate e a demanda por processos dessa natureza estão se popularizando em nossa sociedade, visto pelo significativo número de solicitações de inscrição de bens, práticas ou genericamente lugares ao rol oficial da proteção, tanto em escala nacional, quanto internacional. De outra parte, outras agências sociais robustecem procedimentos de salvaguarda de memórias, histórias, patrimônios e identidades concernentes à sua formação cultural. Ainda são necessários estudos que qualifiquem e adensem diagnósticos acerca destas realidades em perspectiva interdisciplinar, contudo, a fim de encerrar esta reflexão, indicaremos três dimensões investigativas das dinâmicas escolares de patrimonialização sobre as quais as situações de São Luiz do Paraitinga e Laguna nos permitiram refletir.

a) 0 pensamento urbano tem sofrido diversas transformações nos últimos anos (GORELIK, 2005). As construções das formas espaciais urbanas, da mesma forma, são condicionadas (e condicionam) pela especulação imobiliária, pela segregação dos espaços da cidade, pelas questões da qualidade de vida e da sustentabilidade e por experiências de novas formas de habitar e construir a urbanidade. Esse contexto evidencia que "[...] a complexidade das novas dinâmicas urbanas exige uma abordagem real desde a questão do espaço público e o exercício da cidadania. Se trata de fazer cidade na cidade [...]" (MARTÍNEZ, 2008, p. 4, tradução nossa). As razões de ser da cidade, seus interesses, conflitos e projetos engendram a mobilização de experiências formativas diferenciadas. 
Quando a escola assume funções de proteção patrimonial, mesmo que não definida por órgão oficial específico, a educação patrimonial inscreve-se nas interfaces entre a pedagogia escolar e pedagogia urbana e pode ser redefinida enquanto "[...] tendência socioeducativa inscrita na noção de valor da criação cultural na história humana [...]" (MARTÍNEZ, 2008, p. 9).

b) A educação patrimonial engaja-se, enquanto objetivo social, em estratégias sociopolíticas e pedagógicas para evitar a morte social dos patrimônios (GARCÍA, 2016). $\mathrm{Na}$ primeira situação analisada, São Luiz do Paraitinga, a iminência da perda de seu patrimônio por uma forte enchente desencadeou processos culturais diversificados de protagonismo popular, manifestando inúmeros engajamentos no campo cultural. 0 projeto de transpor obras de José Carlos Monteiro às paredes da edificação estudantil evidencia o papel de transmissão de um legado evidente nessas condições específicas, tanto do ponto de vista social, quanto individual (na condição de profissional atuante naquele espaço escolar nas últimas três décadas). Na segunda, referente à Laguna, identificamos uma experiência de educação patrimonial de longa duração onde aspectos identitários de uma antiga comunidade de pescadores descendentes de açorianos são reconstruídos, a partir da constatação de seu esquecimento. Mediado por tecnologias educativas, o idealizador promove uma reconstrução cultural com base em coleta de informações na comunidade, em intervenções investigativas realizadas por estudantes do ensino fundamental, mas também por consultas na rede mundial de computadores. Investigar essas dinâmicas implica contextualizá-las em uma sociedade de ricas transformações científicas e tecnológicas, mas também uma sociedade em que a lógica mercantil intervém e reduz as possibilidades de uma sociedade educativa (MARTÍNEZ, 2008).

c) Para finalizar, requer que perscrutemos, em intersecção com os estudos em sociologia da educação, os processos de reconhecimento social das culturas e dos patrimônios; as imagens plurais de uma sociedade fragmentada veiculadas através das dinâmicas escolares de patrimonialização (KURI, 2006); e as múltiplas dimensões que conformam as cidades hodiernas. Se a educação escolar no Brasil foi produzida pelos princípios da homogeneização e da unidade nacional, ela é, na atualidade, tensionada pelas novas configurações do campo do patrimônio e pelos dilemas educacionais e políticos de uma sociedade democrática. Investigar as políticas de educação patrimonial exige que descentremos, como anunciado na epígrafe que abriu o presente artigo (ENGUITA, 2016), nosso olhar das árvores em direção ao bosque inteiro.

\section{Referências}

ABREU, Regina. Patrimonialização das diferenças e os novos sujeitos de direito coletivo no Brasil. In: TARDY, Cécile; DODEBEl, Vera (Org.) Memória e novos patrimônios. Marseille: Open Edition Press, 2015. p. 67-93.

CANCLINI, Néstor Garcia. 0 patrimônio cultural e a construção imaginária do nacional. Revista do Patrimônio Histórico e Artístico Nacional, Brasília, DF, n. 23, p. 95-115, 1994.

CANDAU, Joël. Memória e identidade. São Paulo: Contexto, 2016. 
CHUVA, Márcia. Os arquitetos da memória: sociogênese das práticas de preservação do patrimônio cultural no Brasil (anos 1930-1940). Rio de Janeiro: UFRJ, 2009.

DUBET, François. Mutações cruzadas: a cidadania e a escola. Revista Brasileira de Educação, Rio de Janeiro, v. 16, n. 47, p. 289-305, 2011.

ENGUITA, Mariano. La educación en la encrucijada. Madrid: Fundación Santillana, 2016.

GARCÍA, Zaida. Como podemos evitar a morte social do patrimônio cultural? Educação patrimonial, uma área emergente. Mouseion, Canoas, n. 23, p. 41-56, 2016.

GORELIK, Ádrian. A produção da 'cidade latino-americana'. Tempo Social, São Paulo, v. 17, n. 1, p. 111-133, 2005.

IBARRA, Macarena. Patrimônio e comunidade: perspectivas da educação patrimonial chilena (1970-2015). Mouseion, Canoas, n. 23, p. 15-40, 2016.

KURI, Patricia Ramírez. Pensar la ciudad de lugares desde el espacio público en un centro histórico. In: KURI, Patricia Ramírez; DÍAZ, Miguel (Org.). Pensar y habitar la ciudad: afectividad, memoria y significado en el espacio urbano contemporáneo. Barcelona: Anthropos, 2006. p. 105-129.

LONDRES, Cecília. 0 patrimônio em processo: trajetória da política federal de preservação no Brasil. Rio de Janeiro: UFRJ, 2009.

MARTíNEZ, Eusebio Nájera. Esbozos para una pedagogía urbana pertinente a los desarrollos educativos en las ciudades. Polis, Santiago de Chile, n. 20, p. 1-11, 2008.

OLIVEIRA, Laércio Vitorino de Jesus. Memória: um patrimônio irrenunciável - comunidades do Distrito de Ribeirão Pequeno da Laguna. Palhoça: Unisul, 2010.

POLLAK, Michael. Memória, esquecimento, silêncio. Estudos Históricos, Rio de Janeiro, v. 2, n. 3, p. 3-15, 1989.

ROTMAN, Mónica. El campo patrimonial: procesos de configuración y problematización de alteridades. Revista Memória em Rede, Pelotas, v. 1, n. 1, p. 22-42, 2010.

SILVA, Rodrigo Manoel Dias da. Educação patrimonial e a dissolução das monoidentidades. Educar em Revista, Curitiba, n. 56, p. 2017-224, 2015.

SILVA, Rodrigo Manoel Dias da. Educação patrimonial e políticas de escolarização no Brasil. Educação e Realidade, Porto Alegre, v. 41, n. 2, p. 467-489, 2016.

TRILLA, Jaume. Otras educaciones: animación sociocultural, formación de adultos y ciudad educativa. Barcelona: Anthropos, 1993. 
YÚDICE, George. A conveniência da cultura: usos da cultura na era global. Belo Horizonte: UFMG, 2004.

Recebido em: 29.11.2016

Revisões em: 23.02.2017

Aprovado em:21.03.2017

Rodrigo Manoel Dias da Silva é professor da Escola de Humanidades e do Programa de PósGraduação em Educação da Universidade do Vale do Rio dos Sinos (Unisinos), São Leopoldo, RS. Doutor em ciências sociais pela mesma instituição. 